\title{
Hospitalised Eye Injuries in New South Wales, Australia
}

\author{
Jennifer Long ${ }^{*}, 1,2$ and Rebecca Mitchell ${ }^{3}$ \\ ${ }^{I}$ School of Optometry and Vision Science, University of New South Wales, Sydney, Australia \\ ${ }^{2}$ School of Human Movement Studies, University of Queensland, Brisbane, Australia \\ ${ }^{3}$ NSW Injury Risk Management Research Centre, University of New South Wales, Sydney, Australia
}

\begin{abstract}
Purpose: This is the first population-based descriptive study of hospitalised eye injuries in New South Wales (NSW), Australia that also estimates the cost of these injures to the health system. The purpose is to describe the incidence and cause of hospitalised eye injuries in NSW from 1 July 2000 to 30 June 2005.

Method: Hospitalised eye injuries in NSW were obtained from information recorded in the NSW Admitted Patients Data Collection and were identified using relevant International Classification of Disease, version 10 Australian modification (ICD-10-AM) codes pertaining to eye injury.

Results: The annual rate of hospitalised eye injuries for NSW residents was 25.5 per 100,000 population. Males had higher rates of hospitalisation than females and males 20-24 years and females aged 85 years or over had the highest rates of hospitalisation for each gender. Injuries of the eye and orbit were the most common type of injury (40.8\%) and interpersonal violence was the most common type of injury mechanism $(27.4 \%)$. The home was the most common specified location of the incident and eye injuries were identified as work-related in $9.8 \%$ of cases.

Conclusions: Eye injuries are an important cause of hospitalised injury in NSW. Preventive approaches to ocular trauma should be promoted to populations identified at risk.
\end{abstract}

Keywords: Eye injury, hospitalisation, NSW Australia.

\section{INTRODUCTION}

Eye injuries are an issue for public health, irrespective of whether they occur at work, home or during play. An eye injury has the potential to impact on an individual's employment prospects and their capacity to maintain independence; disfigurement can result in less tangible issues, such as appearance and sense of self worth.

There is limited population-based information regarding the incidence and type of ocular trauma experienced by individuals [1]. From what is known, it appears that men are more likely to sustain an eye injury than women [1-6]. Between $44 \%$ [3] and 60\% [1] of eye injuries in Victoria, Australia were estimated to be work-related. In particular, severe work-related eye injuries (i.e. penetrating injuries or injuries requiring hospitalisation) have been reported to encompass around 17\% [3] of all eye injuries and represent $1.6 \%$ of occupational eye injuries [2]. Similarly, in the United States, $14 \%$ of serious eye injuries were found to occur in the workplace [7]. However, more recently published studies also report that the home is one of the most common locations for serious eye injuries $[7,8]$.

In the United States, the hospitalised incidence of eye injuries has been decreasing over time, particularly for workrelated eye injuries [4]. It has been surmised that the down-

*Address correspondence to this author at the School of Optometry and Vision Science, UNSW, Australia and School of Human Movement Studies, University of Queensland, Australia; Tel: +61 24782 3472;

E-mail: j.long@unsw.edu.au, jlong@visualergonomics.com.au ward trend in occupational eye injuries may be due to the introduction of occupational health and safety legislation and the promotion of protective eyewear in the workplace $[4,7$, 8]. However, in Australia, the trend of eye injury incidence over time has not been described.

Little is known regarding the incidence and characteristics of hospitalised eye injuries in New South Wales (NSW), Australia's most populous state with around 6.4 million residents [9], nor is there information regarding the direct cost of these injuries to the health service. This study seeks to obtain an estimate of the incidence and cause of hospitalised eye injuries involving NSW residents and to determine the direct cost of hospitalisation for these injuries to the health system.

\section{MATERIALS AND METHODOLOGY}

A descriptive study of hospitalised eye injuries was conducted using a retrospective review of information recorded in the NSW Admitted Patients Data Collection (APDC) during 1 July 2000 to 30 June 2005.

\section{Data Source}

Data from the NSW APDC include information on inpatient separations for NSW residents from public and private hospitals, private day procedures, and public psychiatric hospitals. It also includes data on episodes of care in hospital, which end with the discharge, transfer, or death of the patient, or when the service category for the admitted patient changes. The hospitalisation data were coded using the Australian Modification of the International Classification of Diseases (ICD-10-AM) [10-13]. 
The direct hospitalisation cost for each admission for an eye injury was calculated for the 1 July 2003 to 30 June 2005 period for public hospitals only from the Commonwealth Department of Health and Ageing's National Hospital Cost Data Collection [14]. The average direct cost per diagnosisrelated group (DRG) for the procedures conducted for eye injuries were multiplied by the number of these procedures conducted and the total added to calculate the direct cost.

\section{Case Selection Criteria}

Hospitalised eye injuries of NSW residents were identified using the following criteria:

- the hospitalisation was for a patient who was a resident of NSW; and

- the ICD-10-AM principal diagnosis consisted of an injury to the eye: S00.1, S00.2, S01.1, S02.3, S04.0S04.2, S04.4, S05, T15, T90.4, H05.5, H44.6, and H44.7.

Hospitalisations as a result of an eye injury that met any of the following criteria were considered to be work-related:

- the activity code in ICD-10-AM versions 2 to 4 indicated the injured person was working at the time of the injury (i.e. Y93.2 or U73.0 to U73.09);

- $\quad$ payment status was 'compensable - NSW workers' compensation' (i.e. '40'); or

- $\quad$ supplementary factors related to causes of morbidity and mortality was a 'work-related condition' (i.e. 'Y96').

\section{Data Management and Analysis}

Hospitalisations relating to transfers between hospitals and changes in the service category (e.g. a change from acute to rehabilitation for a patient during one episode of care in a single facility) were excluded in order to attempt to partly eliminate 'multiple counts' [15].

Analyses were performed using SAS [16]. Age- and sexspecific population estimates at 31 December of each of the years under study were obtained from the NSW Health Department. These correspond to the mid-point of each financial year of hospitalisation data and were extrapolated from Australian Bureau of Statistics (ABS) population estimates at 30 June [15]. Direct age standardised rates were calculated using the estimated Australian residential population at 30 June 2001 as the standard population. Ninety-five percent confidence intervals $(95 \% \mathrm{CI})$ were calculated assuming a Poisson distribution [17]. Because of over-dispersion, negative binomial regression was used to examine the statistical significance of changes in the trend over time of hospitalised eye injuries [18].

The NSW APDC includes hospitalisations of NSW residents that occurred in another state or territory, identified by their state of residence. These hospitalisations were included in the analysis to ensure the numerator and the denominator were as closely matched as possible. However, hospitalisation data for NSW residents in another state or territory were not available for 2004-05 at the time of analysis and are therefore not included in the analysis. They were estimated based on location of residence of the injured individuals during the past 4 years to include 59 admissions or $3.4 \%$ of hospitalised eye injuries based on the average of the past four years.

\section{RESULTS}

There were $8,485 \mathrm{NSW}$ residents hospitalised as a result of an eye injury during 2000-01 to 2004-05, giving an annual rate of 25.5 per 100,000 population (Table 1). The rate of hospitalisation for eye injuries during 2000-01 to 2004-05 did not change significantly per year $(\mathrm{p}<0.9)$. Just under three-quarters of all hospitalised eye injuries occurred to males $(71.9 \%)$, with males having two and a half times the rate of hospitalisation for eye injuries than females (Table $\mathbf{1}$ ). Males aged 20-24 years and females aged 85 years or over had the highest rates of hospitalisation for an eye injury for each gender (Fig. 1).

Injuries of the eye and orbit were the most common type of eye injury requiring hospitalisation (40.8\%) (Table 2) and this trend was consistent for all age groups. Foreign bodies entering the eye were the most common reason for hospitalisation of children younger than 9 years $(21.8 \%, \mathrm{n}=1780-4$ years; $13.2 \%, \mathrm{n}=108$ 5-9 years). Fractures were most common in youth and young adults: $15-19$ years $(11.9 \%, \mathrm{n}=231)$, $20-24$ years $(16.4 \%, \mathrm{n}=317)$, and $25-29$ years $(14.6 \%$, $\mathrm{n}=283)$. In particular, young males (15-34 years) made up almost half $(48.2 \%, \mathrm{n}=935)$ of all fractures. Injuries to the eye and orbit were the most common reason for hospitalisation of individuals older than 75 years $(39.2 \%, \mathrm{n}=333)$. Retention of an old foreign body in the eye were common in

Table 1. Hospitalised Eye Injuries of NSW Residents by Year and Gender, Number, Rate and 95\% CI, 2000-01 to 2004-05

\begin{tabular}{|c|c|c|c|c|c|c|c|c|c|}
\hline \multirow{2}{*}{ Year } & \multicolumn{3}{|c|}{ Male } & \multicolumn{3}{|c|}{ Female } & \multicolumn{3}{|c|}{ Persons } \\
\hline & $\mathbf{n}$ & Rate $^{1}$ & $95 \% \mathrm{CI}^{2}$ & $\mathbf{n}$ & Rate $^{1}$ & $95 \% \mathrm{CI}^{2}$ & $\mathbf{n}$ & Rate $^{1}$ & $95 \% \mathrm{CI}^{2}$ \\
\hline 2000-01 & 1,166 & 35.8 & $33.8-37.9$ & 413 & 12.2 & $11.0-13.4$ & 1,579 & 24.2 & $23.0-25.4$ \\
\hline 2001-02 & 1,321 & 40.0 & $37.9-42.3$ & 482 & 13.7 & $12.5-15.0$ & 1,803 & 27.1 & $25.9-28.4$ \\
\hline $2002-03$ & 1,290 & 39.0 & $36.9-41.2$ & 538 & 15.3 & $14.1-16.7$ & 1,828 & 27.4 & $26.2-28.7$ \\
\hline 2003-04 & 1,245 & 37.6 & $35.6-39.8$ & 504 & 14.3 & $13.1-15.7$ & 1,749 & 26.1 & $24.9-27.4$ \\
\hline 2004-05 & 1,082 & 32.5 & $30.6-34.5$ & 444 & 12.3 & $11.2-13.5$ & 1,526 & 22.6 & $21.5-23.7$ \\
\hline Total & 6,104 & 37.0 & 36.1-38.0 & 2,381 & 13.6 & $13.0-14.1$ & 8,485 & 25.5 & $25.0-26.0$ \\
\hline
\end{tabular}

${ }^{1}$ Age-standardised rate per 100,000 population.

${ }^{2} 95 \%$ confidence interval. 


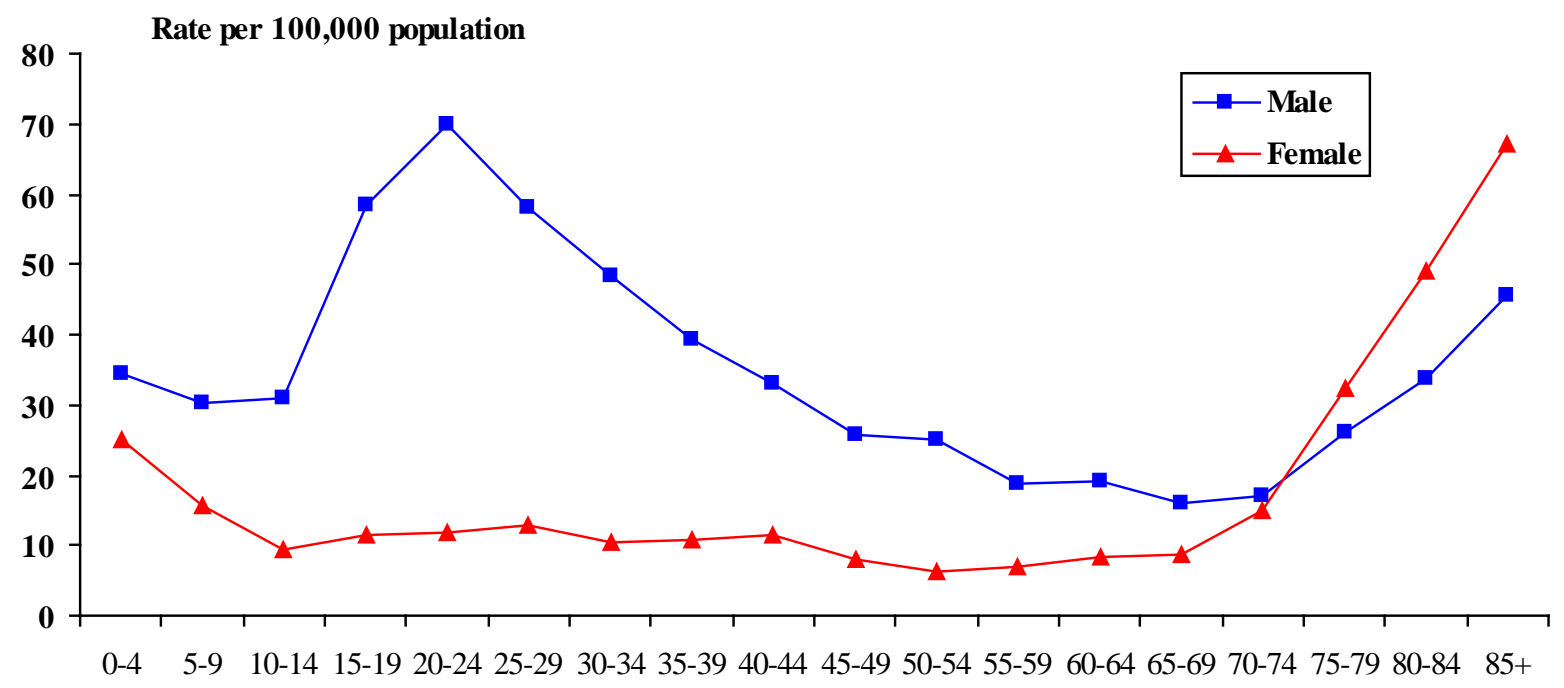

Age group

Fig. (1). Rate of hospitalised eye injuries of NSW residents by age group and gender, 2000-01 to 2004-05 ${ }^{1,2}$.

${ }^{1}$ Age-standardised rate per 100,000 population.

${ }^{2}$ Twelve individuals were excluded as their ages were not known.

$75-79$ year olds $(18.5 \%, \mathrm{n}=31)$ and $80-84$ year olds $(12.5 \%$, $\mathrm{n}=21$ ).

Where an external cause code was present, interpersonal violence $(27.4 \%)$, struck by/ struck against (20.2\%), falls (15.7\%), effects of foreign bodies entering the eye (10.9\%), and motor vehicle crashes $(6.1 \%)$ were the most common types of injury mechanisms that resulted in an eye injury requiring hospitalisation (Table $\mathbf{3}$ ).

The home was the most common specified location where the injury occurred (19.0\%). However, unspecified places accounted for $44.1 \%$ and not known places for $3.2 \%$ of the locations where the eye injury occurred (Table 3 ).

Just less than $10 \%$ of hospitalised eye injuries were identified as being work-related $(\mathrm{n}=833)$. Where an incident was identified as work-related, the majority of injuries occurred to males $(92.1 \%)$ and involved those aged 20-44 years $(64.3 \%)$. Injuries to the eye and orbit $(53.7 \%)$ were the most common type of injury for work-related hospitalisations and these were commonly caused by foreign bodies entering the eye $(25.0 \%)$ or by being struck by/ struck against $(24.1 \%)$ (Table 4).

The direct cost of the hospitalisations following an eye injury in NSW during 1 July 2003 to 30 June 2005 was estimated at $\$ 7,434,186$, with a mean cost of $\$ 181,322$ per admission.

\section{DISCUSSION}

Hospitalised eye injuries represent a serious public health issue for NSW. The annual rate of hospitalised eye injuries in NSW over the 5 year period examined was estimated at 25.5 per 100,000 population. This is within the range of inpatient eye injuries which have been calculated elsewhere to be between 8.1 and 29.1 per 100,000 population [8]. While the incidence of hospitalised eye injuries in NSW appears to be near the top of this range, there are differences between the conduct of these studies, such as use of different case definitions, that hamper direct comparisons.

Males accounted for the majority of hospitalised eye injuries in NSW, representing just less than three-quarters of all hospitalisations. Males had a higher proportion of all injury mechanisms compared to females, except for falls. This difference in proportion between genders is likely to be due to the increased likelihood of males to be involved in interpersonal violence and other incidents where their eye is struck by objects or equipment $[7,19,20]$. Males also accounted for almost all of the work-related eye injury hospitalisations. This is likely to be due to occupational demographics where working males are more likely than females to be employed in hazardous occupations where the risk of injury is higher [21].

Age-related trends for eye injury hospital admissions in the current study peaked in males aged 20-24 years. A peak in this age group was also found in Victoria [3] and in the United States [19]. In the current study, the injury rate for females over the age of 75 years exceeded the injury rate for males of the same age. In fact, the eye injury rate for a female older than 80 years approached the rate of that of a 2024 year old male. Reasons for this high incidence of eye injuries in older females are not entirely clear, but are likely to relate to the incidence of falls in this age group and subsequent fracture of the orbital floor. However, this bimodal distribution of injuries is consistent with that published in other studies [22-24].

Interpersonal violence was the most common injury mechanism associated with a hospitalised eye injury and was greatest in males 20-44 years old $(70.5 \%, \mathrm{n}=1,605)$ and largely accounts for the injury peak for 20-24 year olds. In contrast, in the United States, foreign bodies entering the eye were the most common injury mechanism, accounting for between $41.7 \%$ [4] to $44.6 \%$ [19] of injuries resulting in presentation to an emergency department. While the use of 
Table 2 Hospitalised Eye Injuries of NSW Residents by Injury Type, Number and Percent, 2000-01 to 2004-05

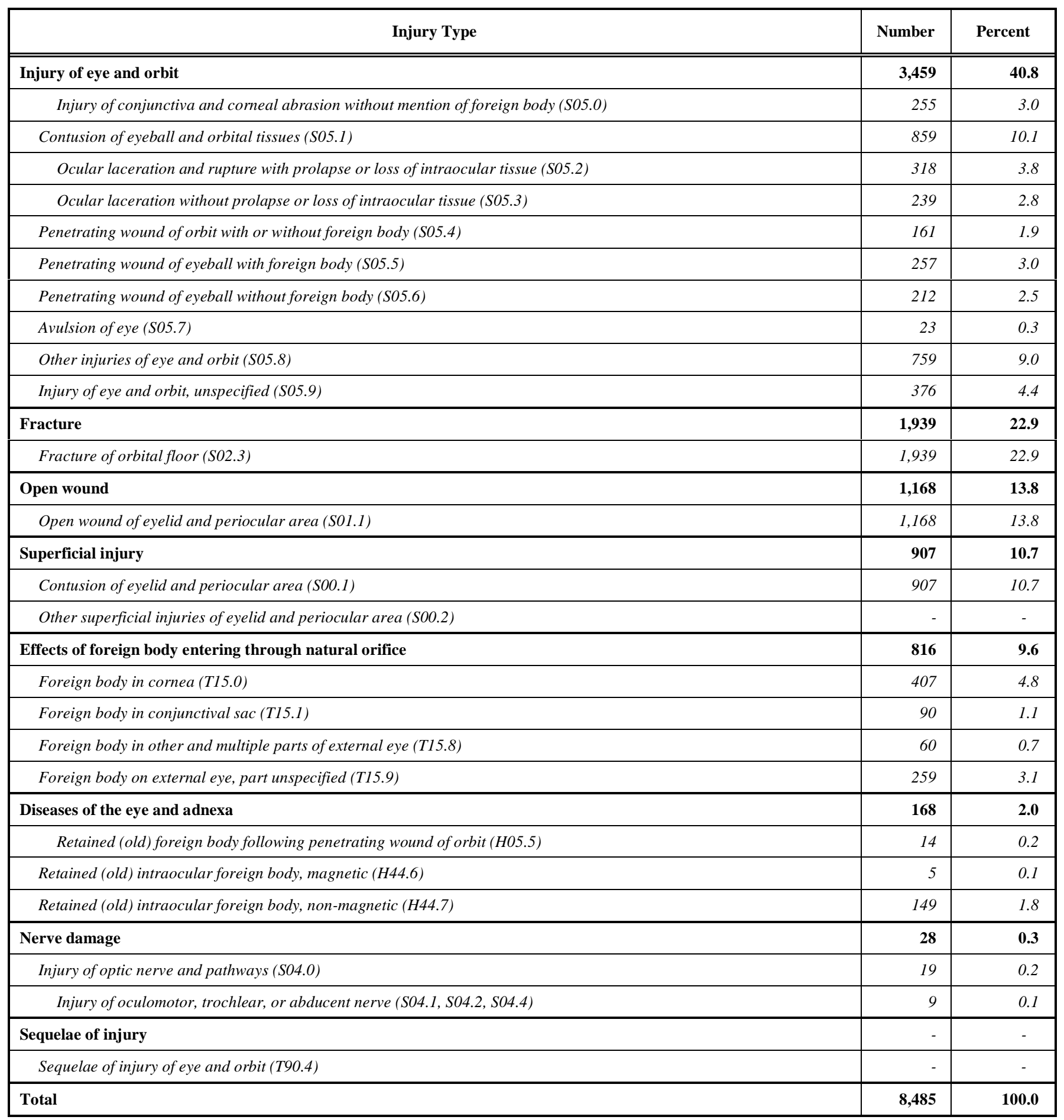

different classification systems makes exact comparisons difficult, it appears that the proportion of foreign bodies entering the eye in the current study $(10.9 \%)$ is far lower than that reported in the United States. However, the United States research used data from emergency department presentations, which is likely to represent less severe eye injuries than the current research where all persons were admitted to hospital.

It has been estimated that severe eye injuries, including those that need hospitalisation and those that result in a per- manent or significant change in ocular function, account for less than $10 \%$ of all eye injuries $[3,7]$. Therefore, many eye injuries, including corneal foreign bodies, lacerations to the eye orbit and welding flash burns, are not represented in this data analysis. Nevertheless, foreign bodies entering the eye were the greatest cause of work-related injuries in this study $(25.0 \%)$. This is consistent with other published reports that foreign bodies are a common mechanism for all work-related eye injuries, both severe and non-severe [2, 3, 19], and may reflect the inherent risks within some occupations. 
Table 3. Hospitalised Eye Injuries of NSW Residents by Injury Mechanism and Location, Number and Percent, 2000-01 to 2004-05

\begin{tabular}{|c|c|c|}
\hline & Number & Percent \\
\hline \multicolumn{3}{|l|}{ Mechanism } \\
\hline Interpersonal violence & 2,275 & 27.4 \\
\hline Struck by/ struck against & 1,680 & 20.2 \\
\hline Falls & 1,305 & 15.7 \\
\hline Foreign body entering the eye & 905 & 10.9 \\
\hline Motor vehicle crash & 506 & 6.1 \\
\hline Cut/pierce & 286 & 3.4 \\
\hline Natural and environmental factors & 194 & 2.3 \\
\hline Poisoning & 118 & 1.4 \\
\hline Other road transport & 84 & 1.0 \\
\hline Machinery & 47 & 0.6 \\
\hline Explosive material & 42 & 0.5 \\
\hline Water transport & 17 & 0.2 \\
\hline Explosion of pressure vessels & 17 & 0.2 \\
\hline Firearms & 10 & 0.1 \\
\hline Attempted self-harm & 10 & 0.1 \\
\hline Fire and burns & 9 & 0.1 \\
\hline Other mechanism & 812 & 9.8 \\
\hline \multicolumn{3}{|l|}{ Location } \\
\hline Home & 1,613 & 19.0 \\
\hline Street and highway & 789 & 9.3 \\
\hline Trade and service area & 460 & 5.4 \\
\hline Sports and athletics area & 422 & 5.0 \\
\hline $\begin{array}{l}\text { School, other institution and public adminis- } \\
\text { trative area }\end{array}$ & 319 & 3.8 \\
\hline Industrial and construction area & 275 & 3.2 \\
\hline Residential institution & 194 & 2.3 \\
\hline Farm & 54 & 0.6 \\
\hline Other specified places & 349 & 4.1 \\
\hline Unspecified place & 3,743 & 44.1 \\
\hline Not known & 267 & 3.2 \\
\hline
\end{tabular}

Around $10 \%$ of all hospitalised eye injuries were identified as work-related. This proportion is less than that reported in the United States for severe ocular trauma identified as work-related (14\%) [7]. It is also less than that reported in Victoria [3] for patients admitted to hospital with work-related eye injuries $(17 \%)$. However, it is likely that the proportion of missing $(38.6 \%)$ and unspecified $(35.7 \%)$ activity codes, which are largely used to identify workrelated hospitalisations in NSW, may have contributed to an under-enumeration of work-related hospitalised eye injuries in the current study.
Table 4. Work-Related Hospitalised Eye Injuries of NSW Residents, Number and Percent, 2000-01 to 2004-05

\begin{tabular}{|c|c|c|}
\hline & Number & Percent \\
\hline \multicolumn{3}{|l|}{ Gender } \\
\hline Male & 767 & 92.1 \\
\hline Female & 66 & 7.9 \\
\hline \multicolumn{3}{|l|}{ Age group } \\
\hline$<15$ & $\#$ & \# \\
\hline $15-19$ & 73 & 8.8 \\
\hline $20-24$ & 106 & 12.7 \\
\hline $25-34$ & 240 & 28.8 \\
\hline $35-44$ & 190 & 22.8 \\
\hline $45-54$ & 133 & 16.0 \\
\hline $55-64$ & 76 & 9.1 \\
\hline $65+$ & 13 & 1.6 \\
\hline Not known & \# & \# \\
\hline \multicolumn{3}{|l|}{ Injury type } \\
\hline Injury of eye and orbit & 447 & 53.7 \\
\hline Foreign body entering the eye & 152 & 18.3 \\
\hline Fracture of orbital floor & 127 & 15.3 \\
\hline $\begin{array}{l}\text { Open wound of eyelid and periocular } \\
\text { area }\end{array}$ & 78 & 9.4 \\
\hline Superficial injury & 17 & 2.0 \\
\hline Nerve damage & 7 & 0.8 \\
\hline Retained old foreign body in eye & 5 & 0.6 \\
\hline \multicolumn{3}{|l|}{ Injury mechanism } \\
\hline Foreign body entering the eye & 208 & 25.0 \\
\hline Struck by/ struck against & 201 & 24.1 \\
\hline Interpersonal violence & 87 & 10.4 \\
\hline Cut/ pierce & 83 & 10.0 \\
\hline Poisoning & 48 & 5.8 \\
\hline Motor vehicle crash & 43 & 5.2 \\
\hline Falls & 35 & 4.2 \\
\hline Machinery & 24 & 2.9 \\
\hline Natural and environmental factors & 9 & 1.1 \\
\hline Explosive materials & 7 & 0.8 \\
\hline Explosion of pressure vessels & 6 & 0.7 \\
\hline Other & 14 & 1.7 \\
\hline Not known & 68 & 8.2 \\
\hline
\end{tabular}

\# Cell size less than 5 cases.

While there are some differences in the epidemiological characteristics of eye injury hospitalisation in both workrelated and other settings, it is likely that the broader community would benefit from injury prevention strategies that have been developed predominantly for the work-related 
setting. For example, in the work setting a number of prevention strategies have been promoted to attempt to prevent eye injuries, such as use of protective goggles or face masks, yet these types of devices have yet to be widely promoted to the general community as safety measures to prevent serious eye injuries.

The most common specified location where the eye injury occurred was the home $(19 \%)$ and this was twice as frequent as any other specified location. The home was also a common location of ocular trauma in Victoria, accounting for $24 \%$ of incident locations [1], and in the United States, accounting for between $41 \%$ [7] to $44.6 \%$ [19] of locations. Again, the differences in the methodology of these studies, particularly the different case definitions adopted for injury severity, are likely to contribute to different proportions found for the locations of the injurious incident.

The calculation of the direct cost of hospitalisation of eye injuries of just less than $\$ 7.5$ million for a 2 year period represents a conservative estimate of the cost of these injuries to the community and to the health system. Other costs, such as hospital overhead costs and indirect costs, including outpatient treatment, loss of productivity, should be taken into account in future studies of the cost impact of eye injuries to NSW.

Limitations of the current analysis include a lack of detail regarding the location where the incident occurred (ie. the location where the injury occurred was unspecified in $44.1 \%$ cases and not known in 3.2\% of cases) and a likely underenumeration of the total number of hospitalised eye injuries as only the principal diagnosis of injury was used to identify eye injuries and for 2004-05 information was not available for NSW residents hospitalised for an eye injury in another Australian state. It is possible that some individuals, particularly with head trauma, also had associated eye injuries that may have been recorded in supplementary diagnoses codes. There is also likely to be an under-enumeration of the identification of work-related cases since the identification of work-relatedness was undertaken using three mechanisms, none of which provide comprehensive coverage [25]. The ability to directly compare the findings of this study to others was hampered by the use of different classification systems, different inclusion criteria (eg. inpatients and/or outpatients) and different case definitions of "severe" or "serious" eye injuries. Similarly, it was difficult to compare the direct costs to the health system with other Australian studies due to different methods of direct cost calculation [3]. Despite these limitations, this study has been the first to describe the incidence of hospitalised ocular trauma and to estimate its cost in NSW.

\section{CONCLUSION}

This study has shown that eye injuries are an important cause of hospitalised injury in NSW. It has also highlighted that young men and elderly women have the highest risk of hospitalised eye injuries and that these groups should be targeted for preventive activities. Overall, injuries to the eye are preventable and relevant precautions should be undertaken to limit the incidence of injury to the eye, particularly in the home environment and the work-related setting.

\section{ACKNOWLEDGEMENTS}

R Mitchell is supported by the NSW Injury Risk Management Research Centre (NSW IRMRC), with core funding provided by the NSW Health Department, the NSW Roads and Traffic Authority, and the Motor Accidents Authority.

The authors wish to thank the Centre for Epidemiology and Research at the NSW Health Department for providing access to the Health Outcomes and Information Statistical Toolkit (HOIST) to obtain data analysed in this study and Mary Potter-Forbes for advice regarding the calculation of direct hospitalisation costs.

\section{REFERENCES}

[1] McCarty C, Fu C, Taylor H. Epidemiology of ocular trauma in Australia. Ophthalmology 1999; 106(9): 1847-52.

[2] Shepherd M, Barker R, Scott D, Hockey R, Spinks D, Pott R. Occupational Eye Injuries. Injury Bulletin: Queensland Injury Surveillance Unit, 2006; No. 90, March.

[3] Fong L. Eye Injuries in Victoria, Australia. Med J Aust 1995; 162 : 64-8.

[4] McGwin G, Hall T, Owsley C. Trends in eye injury in the United States, 1992-2001. Invest Ophthalmol Vis Sci 2006; 47(2): 521-7.

[5 Krishnaiah S, Nirmalan PK, Shamanna BR, Srinivas M, Rao GN, Thomas R. Ocular trauma in a rural population of Southern India. Ophthalmology 2006; 113(7): 1159-64.

[6] Khatry SK, Lewis AE, Schein OD, Thapa MD, Pradhan EK, Katz J. The epidemiology of ocular trauma in rural Nepal (World View). Br J Ophthalmol 2004; 88(4): 456-60.

[7] May DR, Kuhn FP, Morris RE, et al. The epidemiology of serious eye injuries from the Unites States Eye Injury Registry. Graefes Arch Clin Exp Ophthalmol 2000; 238: 153-7.

[8] McGwin G, Owsley C. Incidence of emergency department-treated eye injury in the United States. Arch Ophthalmol 2005; 123: 662-6.

[9] ABS, Australian Bureau of Statistics. 2001 Census Basic Community Profile and Snapshot. Canberra: ABS; 2004. 2004.

[10] National Centre for Classification in Health, ICD-10-AM. $1^{\text {st }}$ ed 1998, Sydney: National Centre for Classification in Health.

[11] National Centre for Classification in Health, ICD-10-AM. $2^{\text {nd }}$ ed. 2000, Sydney: National Centre for Classification in Health.

[12] National Centre for Classification in Health, ICD-10-AM. $3^{\text {rd }}$ ed. 2002, Sydney: National Centre for Classification in Health.

[13] National Centre for Classification in Health, ICD-10-AM. $4^{\text {th }}$ ed. 2004, Sydney: Commonwealth Department of Health.

[14] Commonwealth Department of Health and Ageing. Public sector estimated. Round 8 (2003-04). AR-DRG 4.2 Cost Report 2005 [cited 2007 25/6/2007].

[15] Population Health Division, The Health of the People of NSW. Report of the Chief Health Officer. 2004, NSW Health Department: Sydney.

[16] SAS Institute, SAS: statistical software, version 8.2. 2000, SAS Institute: Cary, North Carolina.

[17] Dobson AJ, Kuulasmaa K, Eberle E, Scherer J. Confidence intervals for weighted sums of Poisson parameters. Stat Med 1991. 10(3): 457-62.

[18] Armitage P, Berry G, Matthews J. Statistical Methods in Medical Research $4^{\text {th }}$ ed. Cornwell: Blackwell Science 2002

[19] McGwin G, Xie A, Owsley C. Rate of eye injury in the United States. Arch Ophthalmol 2005; 2005(123): 970-6.

[20] Negrel A, Thylefors B. The global impact of eye injuries. Ophthalmic Epidemiol 1998; 5(3): 143-69.

[21] Driscoll T, Mitchell R, Mandryk J, Healey S, Hendrie L, Hull B. Work-related fatalities in Australia, 1989 to 1992: an overview. J Occup Health Safety - Aust N Z 2001; 17(1): 45-66.

[22] Wong T, Tielsch J. A population-based study on the incidence of severe ocular trauma in Singapore. Am J Ophthalmol 1999; 128(3): 345-51.

[23] Klopfer J, Tielsch JM, Vitale S, See LC, Canner JK. Ocular trauma in the United States. Eye injuries resulting in hospitalization, 1984 through 1987. Arch Ophthalmol 1992; 110(6): 838-42. 
[24] Tielsch JM, Parver L, Shankar B. Time trends in the incidence of hospitalized ocular trauma. Arch Ophthalmol 1989; 107(4): 51923.
[25] Mitchell R, McClure R, Driscoll T. Refining estimates of hospitalised work-related injury in NSW, 2000-01 to 2004-05. J Occup Health Safety - Aust N Z, In press.

(C) Long and Mitchell; Licensee Bentham Open.

This is an open access article licensed under the terms of the Creative Commons Attribution Non-Commercial License (http://creativecommons.org/licenses/by$\mathrm{nc} / 3.0 /$ ) which permits unrestricted, non-commercial use, distribution and reproduction in any medium, provided the work is properly cited. 